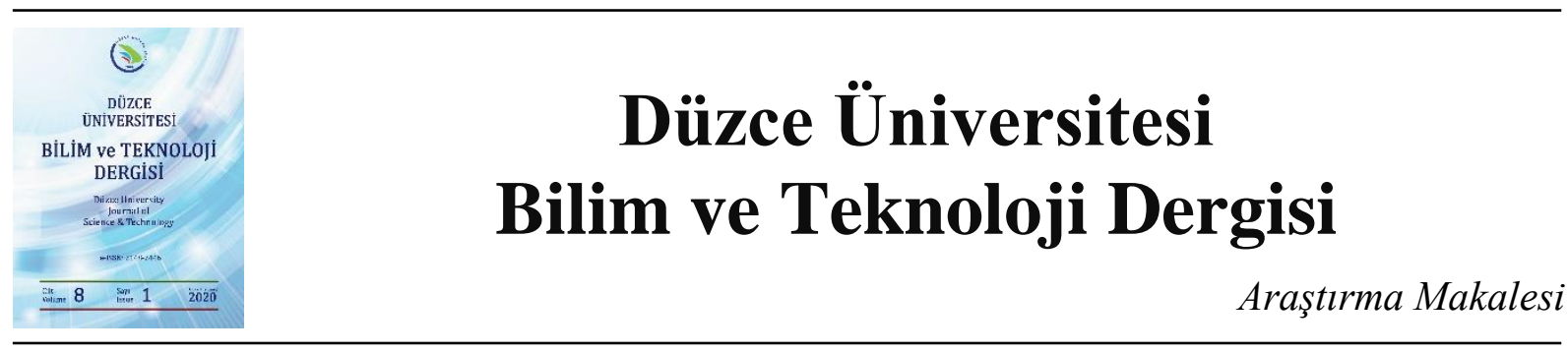

\section{Polimer Katkılı Kompozitlerin Mekanik ve Yalıtım Özelliklerinin İncelenmesi}

\author{
(D) Hüseyin TEMIZ a,*, (D) Müslüm Murat MARAŞ b (D) Fatih KANTARCI ${ }^{\mathrm{b}}$ \\ a İnşaat Mühendisliği Bölümü, Mühendislik Fakültesi, Kahramanmaraş Sütçü İmam Üniversitesi, \\ Kahramanmaraş, TÜRKIYE \\ ${ }^{b}$ Inşaat Mühendisliği Bölümü, Mühendislik Fakültesi, İnönü Üniversitesi, Malatya, TÜRKIYYE \\ * Sorumlu yazarin e-posta adresi: htemiz@ksu.edu.tr
}

DOI : 10.29130/dubited.568812

\begin{abstract}
ÖZET
Enerji kaynaklarının sınırlı miktarda kalması, enerji üretimine göre enerji sarfiyatının daha yüksek olması ve insanların yaşam standartlarının iyileştirilmesi gibi nedenlerle yapıların yalıtımı ve yeni yalıtım malzemelerinin üretilmesi önem arz etmektedir. Ülkemizde, yalıtım özelliği bulunan bazı atık malzemeler amacına uygun değerlendirilmemekte ve çevre kirliliğine neden olmaktadır. Bu sebeple yalıtım, enerji tasarrufu açısından büyük öneme sahiptir. Enerji kaybı yalıtım teknolojileri ile azaltılabilir. Bu çalışmada, uçucu kül, PVC atı̆̆ı, odun talaşı, meşe kabuğu ve pomza gibi malzemelerin beton üretiminde değerlendirilmesi ile ucuz, kaliteli yalıtım malzemesi üretilmesi ve bu malzemelerin inşaat sektörüne kazandırılması amaçlanmıştır. Bitüm ve çimento bağlayıcı faz olarak; uçucu kül, PVC atıkları, talaş ve meşe kabuğu ise agrega olarak kullanılmıştır. Üretilmiş olan 12 adet karışımdan ilk 4 tanesinin bağlayıcı malzemesi bitüm, kalan 8 tanesinin bağlayıcı malzemesi ise çimento olarak belirlenmiştir. Üretilen kompozitler üzerinde ultrases hızı, 1Sı geçirgenlik ve basınç dayanımı testleri uygulanmıştır. Isı geçirgenliği deneyinde en iyi sonuçlar \%27 oranlarında çimento, su, pomza ve \%19 oranında talaş içeren K5 numunesinden elde edilmiştir. Ayrıca, ultrases hızı deneyinde en iyi sonuçlar $\% 12$ PVC atık, $\% 12$ uçucu kül, \%12 pomza, \%12 talaş içeren K8 numunesinde $230 \mathrm{~m} / \mathrm{s}$ olarak elde edilmiştir. Maksimum basınç dayanımı da K8 numunesinden $4 \mathrm{MPa}$ olarak elde edilmiştir. Yapılan deneysel çalışmalar sonucunda üretilen yeni kompozitlerin 1sı ve ses iletimi testlerinde önemli bir iyileşme elde edilmiş ve bu malzemelerin yalıtım teknolojisinde kullanılabileceği ortaya çıkarılmıştır.
\end{abstract}

Anahtar Kelimeler: Uçucu kül, Talaş, Isıl iletkenlik, Ses yalıtımı

\section{Investigation of Mechanical and Insulation Properties of Composites Containing Polymers Additives}

\begin{abstract}
The isolation of buildings and the production of new insulation materials are significant issue because of the limited amount of energy resources, higher energy consumption according to the energy production and improving people's living standards. In our country, some waste materials having insulation properties are not evaluated suitable for their purpose and cause pollution of the environment. So, the insulation has a great importance in terms of energy saving. Energy loss can be reduced by
\end{abstract}


insulating technologies. In this study, it is aimed to produce cheap, high quality insulating materials by evaluating materials such as fly ash, PVC waste, wood shavings, oak bark and pumice in concrete production and bringing these materials to the construction sector. The bitumen and cement were used as binder; fly ash, PVC wastes, sawdust and oak bark were used as aggregate. The binding material of the first 4 of the 12 mixtures produced was determined as bitumen and the remaining 8 mixtures were determined as cement. Ultrasonic pulse velocity, heat permeability and compressive strength tests were applied on the produced composites. A significant improvement in heat conductivity test was obtained from the K5 sample containing $27 \%$ cement, $19 \%$ water, $19 \%$ pumice and $19 \%$ sawdust. The minimum ultrasonic pulse velocity value was obtained as $230 \mathrm{~m} / \mathrm{s}$ from the K8 sample containing $12 \%$ PVC waste, $12 \%$ fly ash, $12 \%$ pumice and $12 \%$ chip. The maximum compressive strength value was also obtained as $4 \mathrm{MPa}$ from K8 sample. A significant improvement was achieved in heat and sound transmission tests of the new composites produced as result of experimental study and it was revealed that these materials could be used in the insulation technology.

Keywords: Fly ash, sawdust, heat conductivity, sound insulation

\section{GİRIS}

Hızlı kentleşme ve doğal kaynakların sınırlı olması geleneksel inşaat malzemelerinde bir eksiklik meydana getirmektedir. Diğer taraftan geleneksel yapı malzemelerinin üretimi için harcanan enerji havayı, suyu ve toprağı kirletmektedir. Artan enerji tasarruflu yapı malzemeleri talebini karşılamak için ucuz maliyetli, çevreyle uyumlu teknolojileri benimsemek ve geleneksel teknikleri yerli malzemelerle geliştirmek gerekmektedir. Tarımsal ve katı atıklar gelişen ülkelerde önemli kaygı oluşturmaktadır [1].

Ekonomiklik, atmosfere düşük $\mathrm{CO}_{2}$ salınımı ve düşük enerji tüketimi gibi değişkenler yeni bir ürün dizayn edilirken hesaba katılan bazı parametrelerdir. Yenilenebilir, yerel ve fazla miktarda bulunan çevreye duyarlı yapı malzemeleri kullanmak bu önemli amaca ulaşmaya katkı sağlayan çözümlerdir. Birçok çalışmada [2-5] küspe, tahıl, saman, mısır sapı, mısır koçanı, pamuk sapları, kenaf, pirinç kabuğu, pirinç, saman, ayçiçeği kabuğu ve sapları, muz sapları, hindistan cevizi, bambu gibi malzemelerin kullanılması ve 1 sı izolasyonlarında denenmesi önerilmiştir. Başka çalışmalarda ise gazete $[5,6]$, bal peteği $[5,7]$ veya polimerik atıkların [8-10] farklı yapı bileşenleri üretiminde kullanımı araştırılmıştır. Diğer taraftan yeni alternatif sürdürülebilir ses izolasyonu yapı malzemeleri toplumsal kaygıların odağında olmuştur. Doğal malzemelerle (örneğin; pamuk, selüloz, kenevir, yün, kil, jüt, kenevir, kenaf, tüy veya Hindistan cevizi) veya yeniden kullanılmış malzemelerle (örneğin; ahşap, branda, köpük, şişe, kot pantolon, kauçuk, polyester, akrilik, fiberglas, halı veya mantar) üretilmiş ses izolasyon ürünleri zaten yerleşmiş çözümlerdir $[5,11]$.

Çevre kirliliğinden dolayı yapı malzemeleri endüstrisine artan bir talep bulunmaktadır. Barınma ihtiyacını karşılamak için tuğla, çimento, agrega, çelik, alüminyum, ahşap ve kaplama gibi yapı malzemelerine yoğun bir ihtiyaç vardır $[1,12]$. Çimento, tuğla ve çelik gibi geleneksel yapı malzemelerinin üretimi çok fazla miktarda ısı ve elektrik enerjisi harcamaktadır ve su, hava ve çevre kirliliği oluşturmaktadır. Uygun yapı malzemelerinin kullanımı yeterli ilgi çekmemektedir. Geleneksel ve tarımsal atıkların ortadan kaldırılması gelişen ülkelerde ayrıca bir sorundur [1, 13]. Sadece Asya kıtasında yıllık olarak 4.4 milyar ton katı atık meydana gelmektedir [1].

İzolasyon yapılarda enerji tüketiminin azaltılması için en faydalı yöntemdir ve 1sıtma-soğutma yükü ile enerji tüketimi üzerine doğrudan etkisi vardır. Bu nedenle bina izolasyonunun performansı izolasyonda kullanılan malzemenin termal özellikleri ve izolasyon yöntemi ile belirlenir. İzolasyon yöntemleri ve malzemeleri üzerine yapılan araştırma ve çalışmalar şimdiye kadar çeşitli şekillerde gerçekleştirilmiştir. Ancak, yeni yapılara uygulanan değişik izolasyon malzemeleri ve sistemleri üzerine faydalı veriler 
oldukça eksiktir. Özellikle binalarda izolasyon ve ses yalıtımı hakkında standartlara uygun olarak dönüştürülen kompozit malzemeler üzerine çalışmalar eksiktir [14].

Son yıllarda düşük maliyetli yüksek performanslı yeni malzemeler üretmek için giderek artan çalışmalar yapılmaktadır. "Yenilenebilir, geri dönüşümlü, sürdürülebilir enerji" gibi sloganlar ve artan çevresel farkındalık ile çevreyle dost malzeme üretimi üzerine yoğunlaşılmıştır. İstenen yapısal ve tasarım gereksinimlerini karşılamak için malzemelerin değişimi veya gelişimi ile çelişen konularda tavizler verilmektedir. Bu sorun malzeme seçimi ve dizaynında çok amaçlı optimizasyonlara başvurarak üstesinden gelinebilir. Doğal ya da sentetik güçlendirme ve çeşitli matris malzemeleri kullanarak hazırlanan kompozit malzemeler bu düşünceye dahildir. Bu malzemelerin gelişimi sadece malzeme bilimi için motive edici faktör olmamış aynı zamanda dünya çapında insanların yaşam standartlarını yükseltmeye imkan sağlamıştır. Bina ve 1sı izolasyon malzemeleri, polimer kompozitler gibi çeşitli inorganik malzemeler tarımsal atıkları kullanarak üretilebilir. Doğada organik olarak bulunan tarımsal atıklar, karbon ve diğer yararlı malzeme ve kimyasalların kaynağıdır. Ayrıca atık malzemeler entegre bir yaklaşım ile yararlı malzemeler gibi diğer alanlarda kullanılabilir. Hindistan, Malezya, Endonezya, Filipinler, Brezilya gibi diğer Afrika ülkeleri, Hindistan cevizi esaslı malzemeler, kauçuk ve palmiye yağı sanayi atıkları, pirinç kabuğu gibi tarımsal atık malzemelerin değerlendirilmesinde ulusal projeler uygulamaktadirlar [15].

Kompozit terimi yüksek performanslı malzemeler için kullanılmaktadır. Bir malzemeye farklı malzemelerin karıştırılmasıyla daha iyi özellikler elde edilebilir [16, 17]. Silis dumanı, uçucu kül, granüle yüksek firın cürufu gibi mineral katkılar, mineral katkı maddesi veya çimento yerine kullanıldığı zaman betonun mühendislik özelliklerini geliştirirler. Bu mineral katkılar arasında uçucu kül santrallerde toz kömürün yakılma ürünü olan ince taneli kalıntı atık malzemedir. Uçucu kül beton üretiminde dünya çapında 50 yılı aşkın bir süredir kullanılmaktadır. Kütle betonlarında, geleneksel betonlarda ve yüksek performanslı betonlarda işlenebilirliği arttırmak, hidratasyon 1sısını ve erken yaşlarda çatlak oluşumunu azaltmak ve özellikle uzun vadede mekanik ve durabilite özelliklerini geliştirmek için kullanılmaktadır [18].

Bu çalışmada, atık ahşap talaşını blok üretiminde değerlendirerek ucuz, kaliteli yalıtım malzemesi üretmek ve inşaat sektörüne kazandırmak amaçlanmıştır. Bu amaçla bitüm ve çimento bağlayıcı faz; uçucu kül, PVC atık, odun talaşı ve meşe kabuğu dağınık faz olarak planlanmıştır ve 12 adet kompozit numunesi üretilmiştir. Bu numunelerden 4 tanesinin bağlayıcı malzemesi bitüm, 8 tanesinin bağlayıcı malzemesi ise çimento olarak belirlenmiştir. Kompozitlerin üretilmesinde ateş sobalarında isınma amaçlı kullanılan ahşap talaşı, meşe kabuğu, doğrama atölyelerinde işlenen PVC atığı ve pomza kullanılmıştır. Üretilen kompozit numunelerin ultrases hızı, 1sıl iletkenlik ve basınç dayanımı değerleri elde edilmiştir.

\section{MATERYAL VE YÖNTEM}

\section{A. MALZEMELER}

Araştırma için AC75-100 penetrasyonlu bitüm Kahramanmaraş (K.Maraş) Belediyesinden, CEM I 42.5 Portland çimentosu K.Maraş Çimento Fabrikasından, uçucu kül K.Maraş Tekstil Boya Fabrikasından, pomza Kayseri'den, ahşap ve PVC ise K.Maraş Organize Sanayi bölgesinden temin edilmiştir. Uçucu külün kimyasal bileşimi Tablo 1'de; CEM I 42.5 Portland çimentosunun kimyasal bileşimi ise Tablo 2'de verilmiştir.

Tablo 1. Uçucu külün kimyasal özellikleri

\begin{tabular}{|c|c|c|c|c|c|c|c|c|c|}
\hline $\begin{array}{c}\text { Uçucu Kül, } \\
(\%)\end{array}$ & $\mathrm{SiO}_{2}$ & $\mathrm{Al}_{2} \mathrm{O}_{3}$ & $\mathrm{Fe}_{2} \mathrm{O}_{3}$ & $\mathrm{CaO}$ & $\mathrm{MgO}$ & $\mathrm{K}_{2} \mathrm{O}$ & $\mathrm{Na}_{2} \mathrm{O}$ & $\mathrm{SO}_{3}$ & Kızdırma kayb1 \\
\cline { 2 - 9 } & 34.17 & 18.88 & 15.13 & 20.55 & 3.42 & 2.02 & 0.60 & 2.16 & 2.10 \\
\hline
\end{tabular}


Tablo 2. CEM I 42.5 çimentosunun kimyasal özellikleri

\begin{tabular}{|c|c|c|c|c|c|c|c|c|}
\hline $\begin{array}{c}\text { CEM I 42.5, } \\
(\%)\end{array}$ & $\mathrm{SiO}_{2}$ & $\mathrm{Al}_{2} \mathrm{O}_{3}$ & $\mathrm{Fe}_{2} \mathrm{O}_{3}$ & $\mathrm{CaO}$ & $\mathrm{MgO}$ & $\mathrm{Na}_{2} \mathrm{O}+0.658 \mathrm{~K}_{2} \mathrm{O}$ & $\mathrm{SO}_{3}$ & K. kayb1 \\
\cline { 2 - 9 } & 20.21 & 4.62 & 3.34 & 63.40 & 2.52 & 0.41 & 2.20 & 2.95 \\
\hline
\end{tabular}

\section{B. MALZEMELERIN KARIŞIM ORANLARI VE NUMUNELERIN HAZIRLANMASI}

\section{B. 1. Bitüm Esaslı Kompozitler}

Çalışmada üretilen ilk dört karışımın bağlayıcı maddesi bitümdür. Malzemeler farklı oranlarda karıştırılmış ve ultrases hızı, 1sı geçirgenlik ve basınç dayanımı testlerine tabi tutulmuştur. Bitüm esaslı kompozitlerin karışım oranları Tablo 3'de verilmiştir.

Tablo 3. Bitüm esaslı kompozitlerin karışım oranları

\begin{tabular}{|c|c|c|c|c|c|}
\hline Numune Kodu & Karışım Bilgileri & Meşe kabuğu & Talaş & Katran & Zift \\
\hline \multirow{2}{*}{ K1 } & Miktar, (gr) & 2310 & 0 & 330 & 660 \\
\cline { 2 - 6 } & Oran, (\%) & 70 & 0 & 10 & 20 \\
\hline \multirow{2}{*}{ K2 } & Miktar, (gr) & 760 & 760 & 330 & 685 \\
\cline { 2 - 6 } & Oran, (\%) & 30 & 30 & 13 & 27 \\
\hline \multirow{2}{*}{ K3 } & Miktar, (gr) & 1900 & 0 & 190 & 380 \\
\cline { 2 - 6 } & Oran, (\%) & 77 & 0 & 7.7 & 15.3 \\
\hline \multirow{2}{*}{ K4 } & Miktar, (gr) & 2170 & 0 & 190 & 355 \\
\cline { 2 - 6 } & Oran, (\%) & 80 & 0 & 7 & 13 \\
\hline
\end{tabular}

Zift ve katran miktarı toplam zift, katran karışımının \%67 zift ve \%33 katran olacak şekilde seçilmiştir. Zift ve katran karışımı elektrikli ısıtıcı ile 1sıtılmıştır (Şekil 1). Isıtılan karışıma etüvde kurutulmuş meşe kabuğu talaşı (Şekil 2, 3) eklenip karıştırma kabında homojen olacak şekilde 1sıtıcı üzerinde karıştırılmıştır (Şekil 4). Meşe kabuğu miktarı ile ilgili belirli bir standart olmadığı için deneme sınama yoluyla seçilmiştir. Zift ve katranının kısa sürede katılaşacağı göz önüne alınarak numune kalıbı, spatula, mala vb. kullanılan aletler ısıtılmıştır.

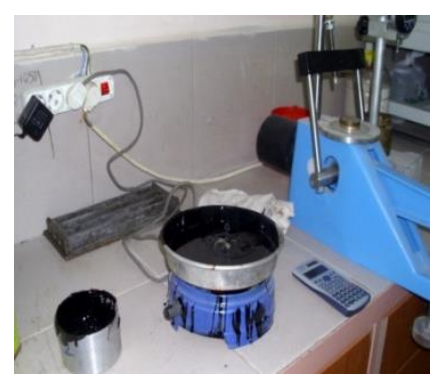

Şekil 1. Zift ve katranın eritilmesi

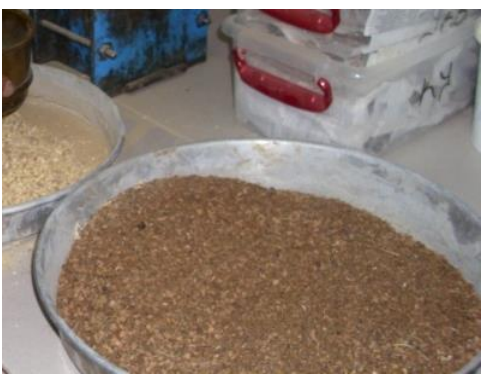

Şekil 2. Meşe kabuğu

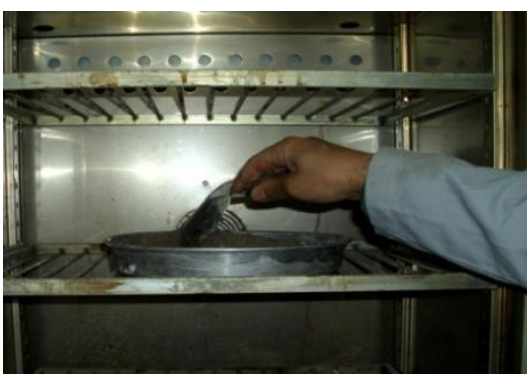

Şekil 3. Etüvde kurutma 

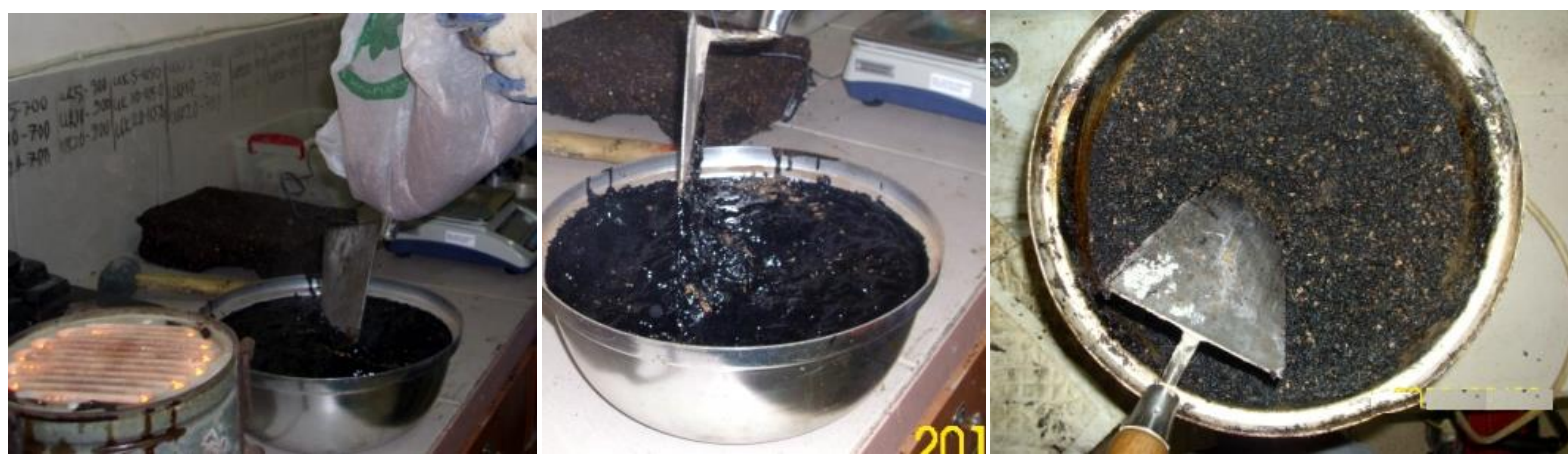

Şekil 4. Malzemelerin karıştırılması

Kalıbın içi hafifçe yağlandıktan sonra karışım kalıplara yerleştirilmiş (Şekil 5) ve pres cihazında 1.5 ton yük uygulanarak sıkıştırılmıştır (Şekil 6). Pres cihazı numune üzerinde bekletilmemiştir. Numuneler pres cihazından alınmış ve küre bırakılmıştır. Kalıptan çıkarılmış numuneler Şekil 7'de verilmiştir. Bitüm esaslı kompozitlerden K4 numunesi plastik bağlayıcılı harçla sıvanmıştır (Şekil 8).

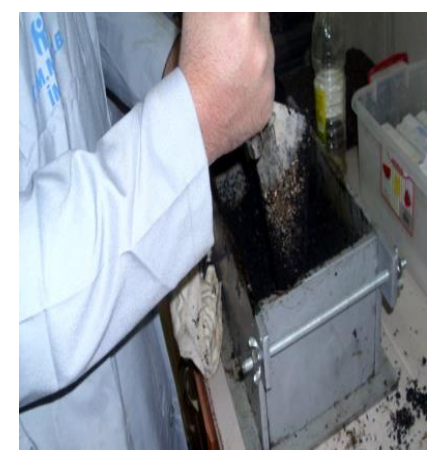

Şekil 5. Karışımın kalıba yerleştirilmesi

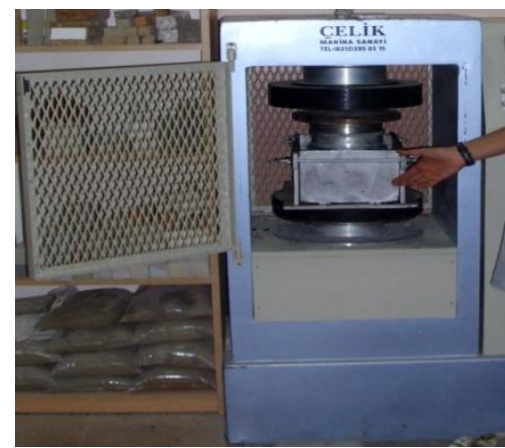

Şekil 6. Üretilen kompozitlerin sıkıştırılması

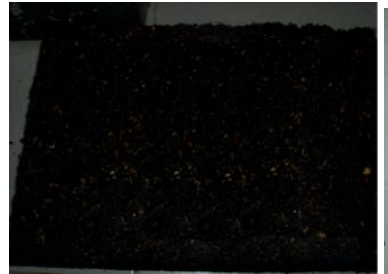

K1

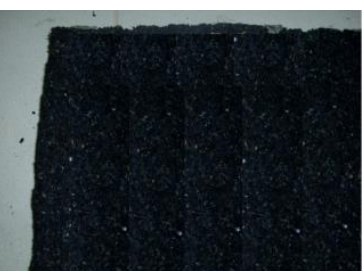

$\mathrm{K} 2$

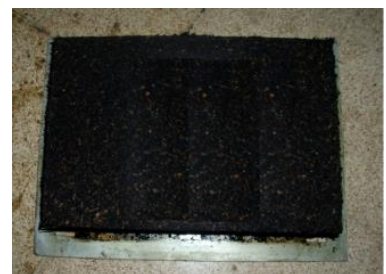

$\mathrm{K} 3$

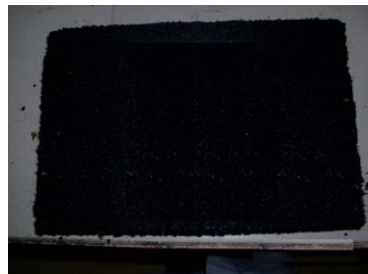

K4

Şekil 7. Kalıptan çıkarılmış bitüm esaslı kompozitler

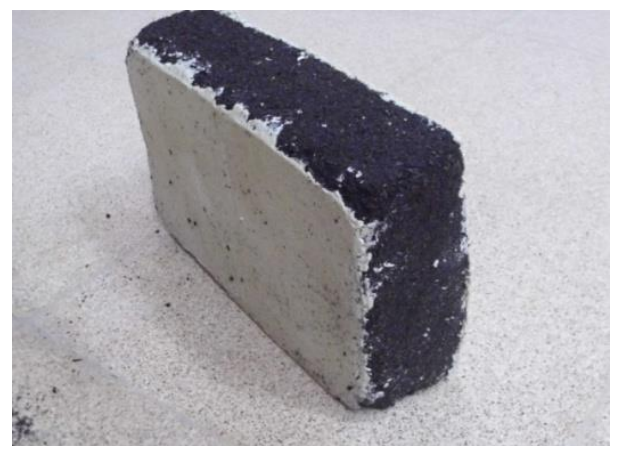

Şekil 8. Plastik bağlayıcı harçla sıvanmış K4 numunesi 


\section{B. 2. Çimento Esaslı Kompozitler}

Çimentolu karışımlarda bitümlü karışımlardan farklı olarak pomza, PVC atı̆ğ ve uçucu kül kullanılmıştır. Çimento esaslı kompozitlerin karışım oranları Tablo 4'te verilmiştir.

Tablo 4. Çimento esaslı kompozitlerin karışım oranları

\begin{tabular}{|c|c|c|c|c|c|c|c|}
\hline Numune Kodu & $\begin{array}{c}\text { Karışım } \\
\text { Bilgileri }\end{array}$ & Çimento & Su & Pomza & Talaş & PVC atık & Uçucu kül \\
\hline \multirow{2}{*}{ K5 } & Miktar, (gr) & 1000 & 1000 & 1000 & 705 & 0 & 0 \\
\cline { 2 - 8 } & Oran, (\%) & 27 & 27 & 27 & 19 & 0 & 0 \\
\hline \multirow{2}{*}{ K6 } & Miktar, (gr) & 1200 & 1120 & 1000 & 540 & 0 & 0 \\
\cline { 2 - 8 } & Oran, (\%) & 31 & 29 & 26 & 14 & 0 & 0 \\
\hline \multirow{2}{*}{ K7 } & Miktar, (gr) & 1200 & 1080 & 1000 & 360 & 360 & 0 \\
\cline { 2 - 8 } & Oran, (\%) & 30 & 27 & 25 & 9 & 9 & 0 \\
\hline \multirow{2}{*}{ K8 } & Miktar, (gr) & 1170 & 1080 & 500 & 500 & 500 & 500 \\
\cline { 2 - 8 } & Oran, (\%) & 28 & 26 & 12 & 12 & 12 & 12 \\
\hline \multirow{2}{*}{ K9, 10, 11, 12 } & Miktar, (gr) & 1150 & 1060 & 970 & 375 & 375 & 500 \\
\cline { 2 - 8 } & Oran, (\%) & 26 & 24 & 22 & 8.5 & 8.5 & 11 \\
\hline
\end{tabular}

İlk olarak uçucu kül (Şekil 9), PVC atık (Şekil 10), su, çimento, talaş, pomza (Şekil 11) homojen şekilde kürekle karıştırılmıştır (Şekil 12).

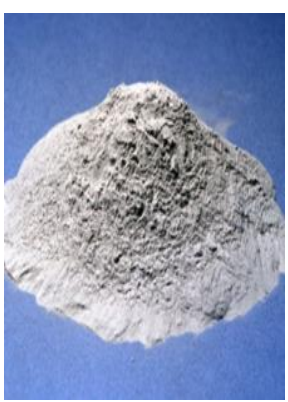

Şekil 9. Uçucu kül

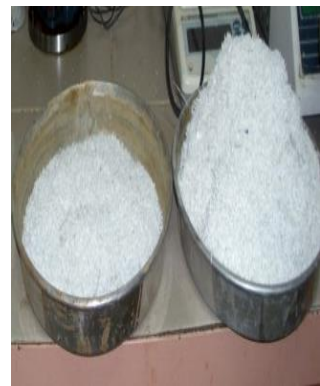

Şekil 10. PVC atık

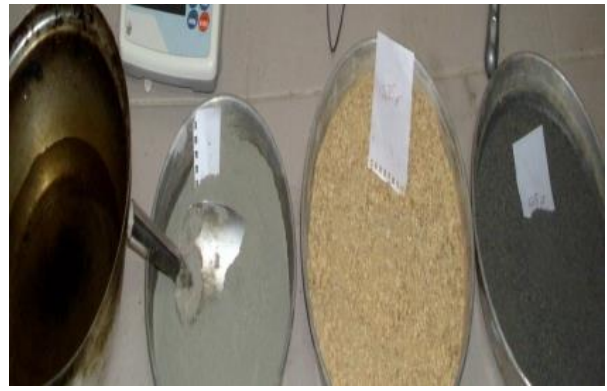

Şekil 11. Su, çimento, talaş, pomza
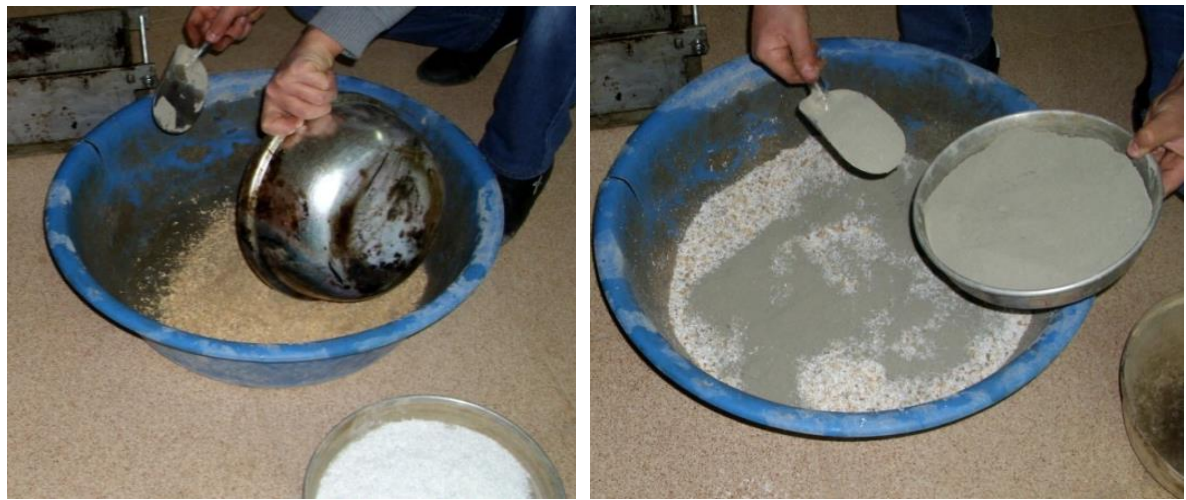

Şekil 12. Malzemelerin karıştırılması 
Karışıma azar azar su eklenerek karıştırmaya devam edilmiştir. Kalıplar yağlanmış (Şekil 13) ve karışım 3 katman halinde sıkıştııılarak yerleştirilmiştir (Şekil 14). Kalıbın kapağı kapatılmış ve 50 kg yük altında üç gün bekletilmiştir (Şekil 15).

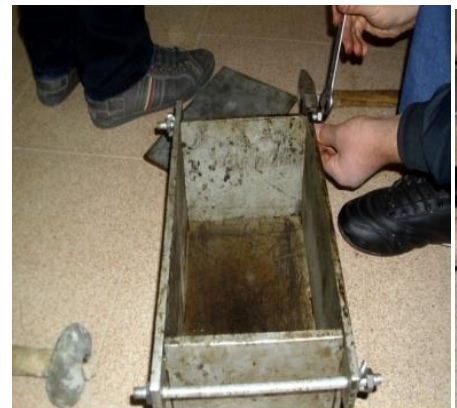

Şekil 13. Yağlama işlemi

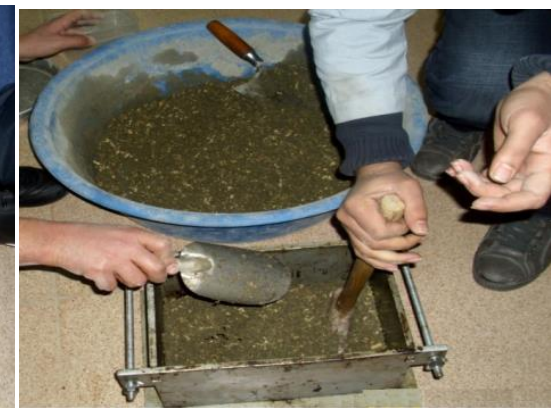

Şekil 14. Sikıştırma işlemi

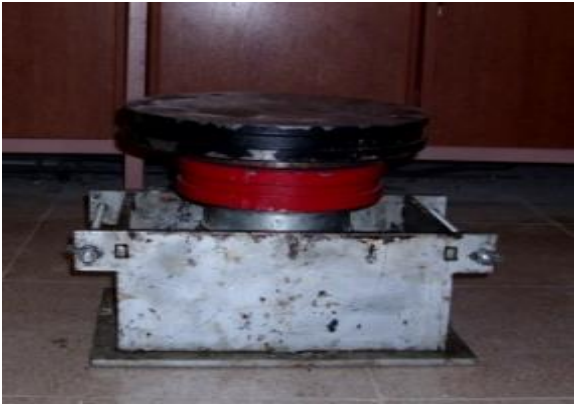

Şekil 15. Yük altında bekletme

Daha sonra numuneler kalıptan çıkarılmıştır. Kalıptan çıkarılmış çimento esaslı kompozit numuneler Şekil 16'da görülmektedir. K10 numunesi ise plastik bağlayıcılı harçla sıvanmıştır.

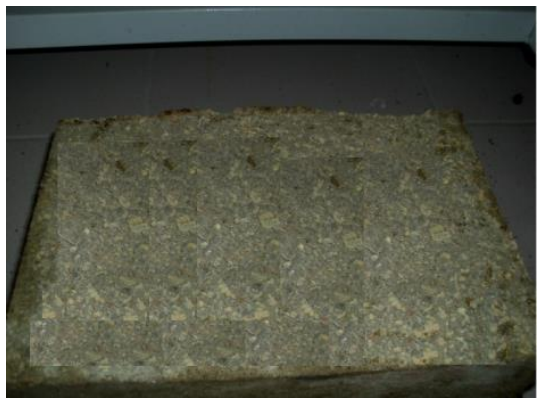

K5

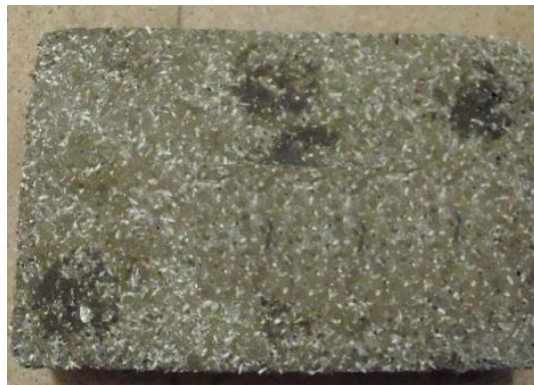

K8

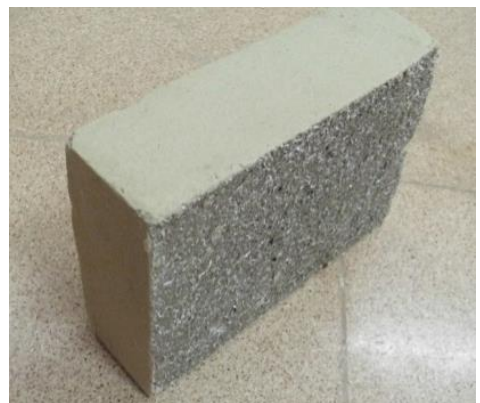

K10

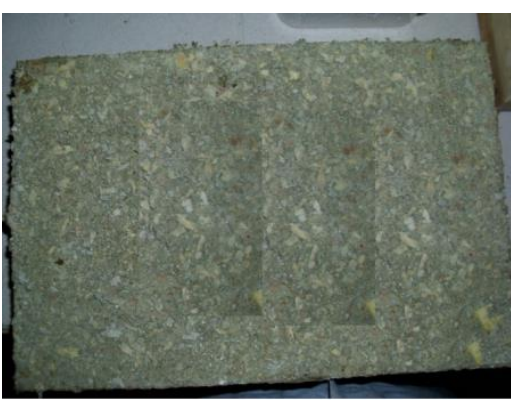

K6

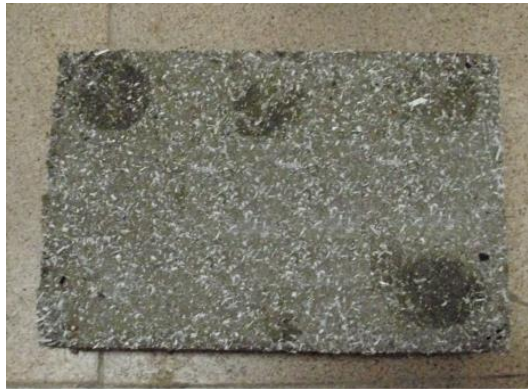

K9

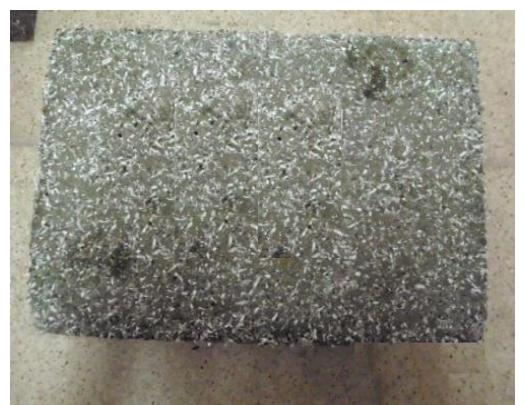

K11

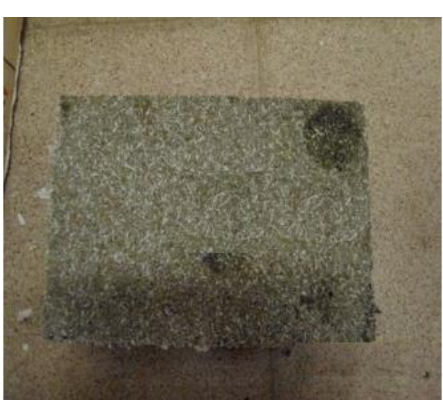

K7

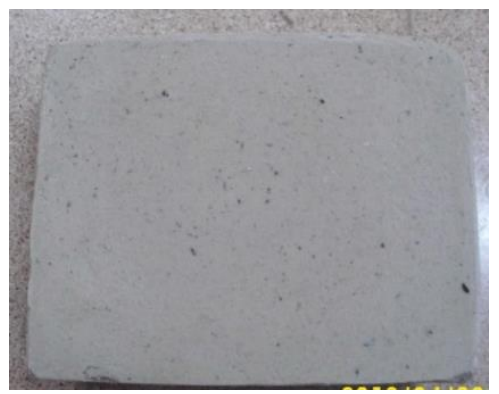

K10

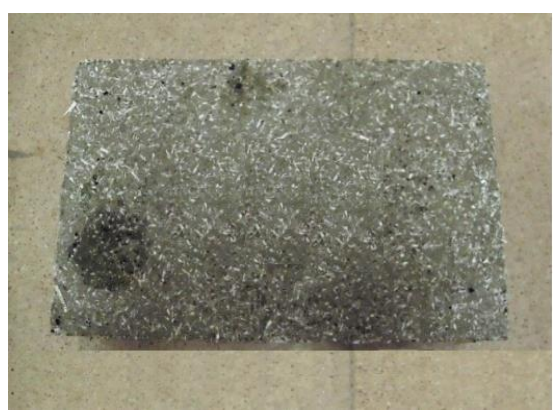

K12

Şekil 16. Kalıptan çıkarılmış çimento esaslı kompozit numuneler 


\section{B.3. Uygulanan Testler}

Üretilen numuneler üzerinde basınç dayanımı, ultrases hızı, 1S1 geçirgenlik testleri yapılmıştır. Elde edilen değerler "Bulgular ve Tartışma" başlığı altında verilmiştir.

\section{B.3.1. Basınç Dayanımı}

Basınç dayanımı deneyi TS EN 12390-3 standardına göre $50 * 50 * 50 \mathrm{~mm}$ boyutlarında numuneler üzerinde yapılmıştır [19]. 28 gün sonunda numuneler otomatik kontrollü pres cihaz ile kırılarak basınç dayanım değerleri ölçülmüştür (Şekil 17). Elde edilen değerler üç adet numunenin ortalaması olarak alınmıştır.
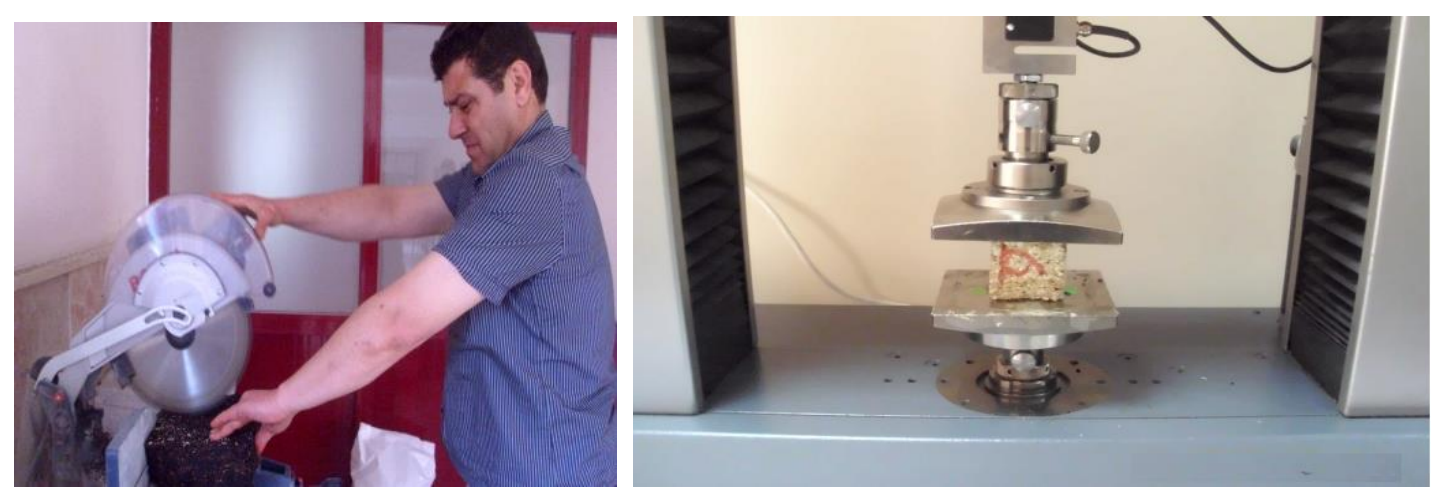

Şekil 17. Basınç dayanımı testi

\section{B.3.2. Ultrases Hizı}

Üretilen kompozitlerin ultrases hızı değerleri ASTM C 597-16 nolu standarda göre yapılmıştır [20]. Ultrases hızı deneyi, 50x50x50 mm ölçülerindeki küp numuneler üzerinde uygulanmıştır (Şekil 18). Beton numunenin bir yüzeyinden gönderilen ses üstü dalganın diğer yüzeyine ne kadar zamanda geçtiği ölçüldükten sonra, dalga hızı Denklem 1 ile hesaplanmaktadır [20].

$\mathrm{V}=(\mathrm{S} / \mathrm{t}) * 10^{6}$

Burada;

$\mathrm{V}=$ Ultrases hiz1, $\mathrm{m} / \mathrm{s}$

$\mathrm{S}=$ Beton bloğun sesüstü dalga gönderilen yüzeyi ile dalganın alındığı yüzeyi arasındaki mesafe, $\mathrm{m}$

$\mathrm{t}=$ Ultrases dalganın gönderilmiş olduğu beton yüzeyinden, alındığı yüzeye kadar geçen zaman, $\mu \mathrm{s}$

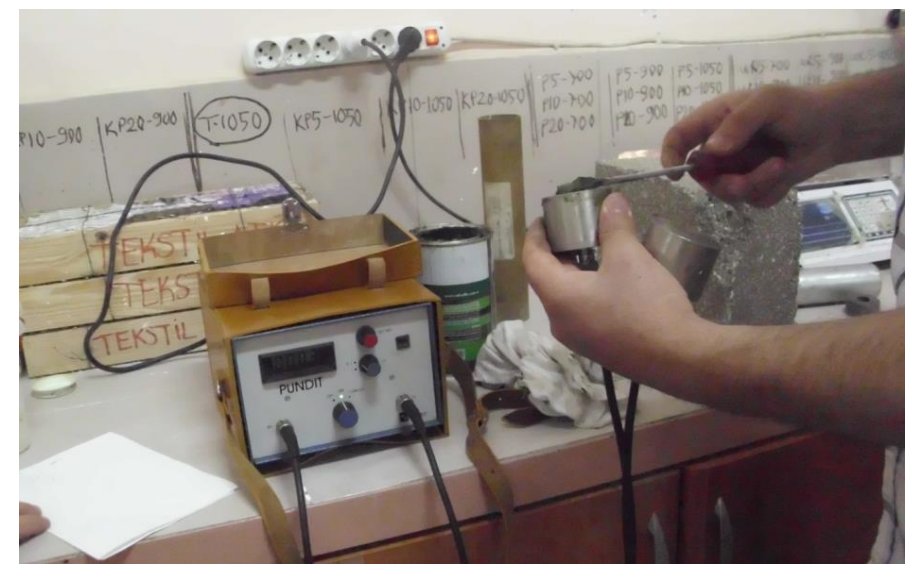

Şekil 18. Ultrases hızı tayini 


\section{B.3.3. Isı Geçirgenlik}

Hazırlanan numunelerin 1s1 geçirgenlik değerleri Şekil 19'da görülen cihaz ile ölçülmüştür. Deney TS 825 standardına göre yapılmıştır [21].

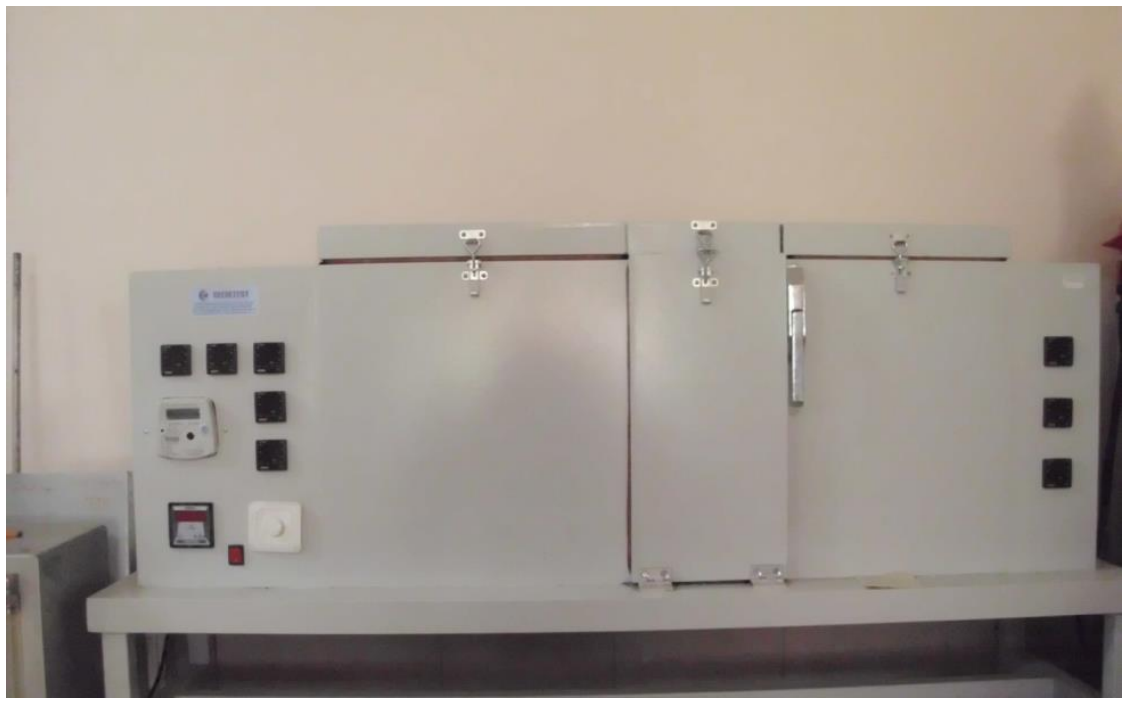

Şekil 19. Isı geçirgenlik cihazı

\section{BULGULAR VE TARTIȘMA}

\section{A. BASINÇ DAYANIMI DEGERLERİ}

Bitüm ve çimento esaslı kompozit numunelerin basınç dayanımı değerleri Şekil 20'de grafiksel olarak gösterilmiştir.

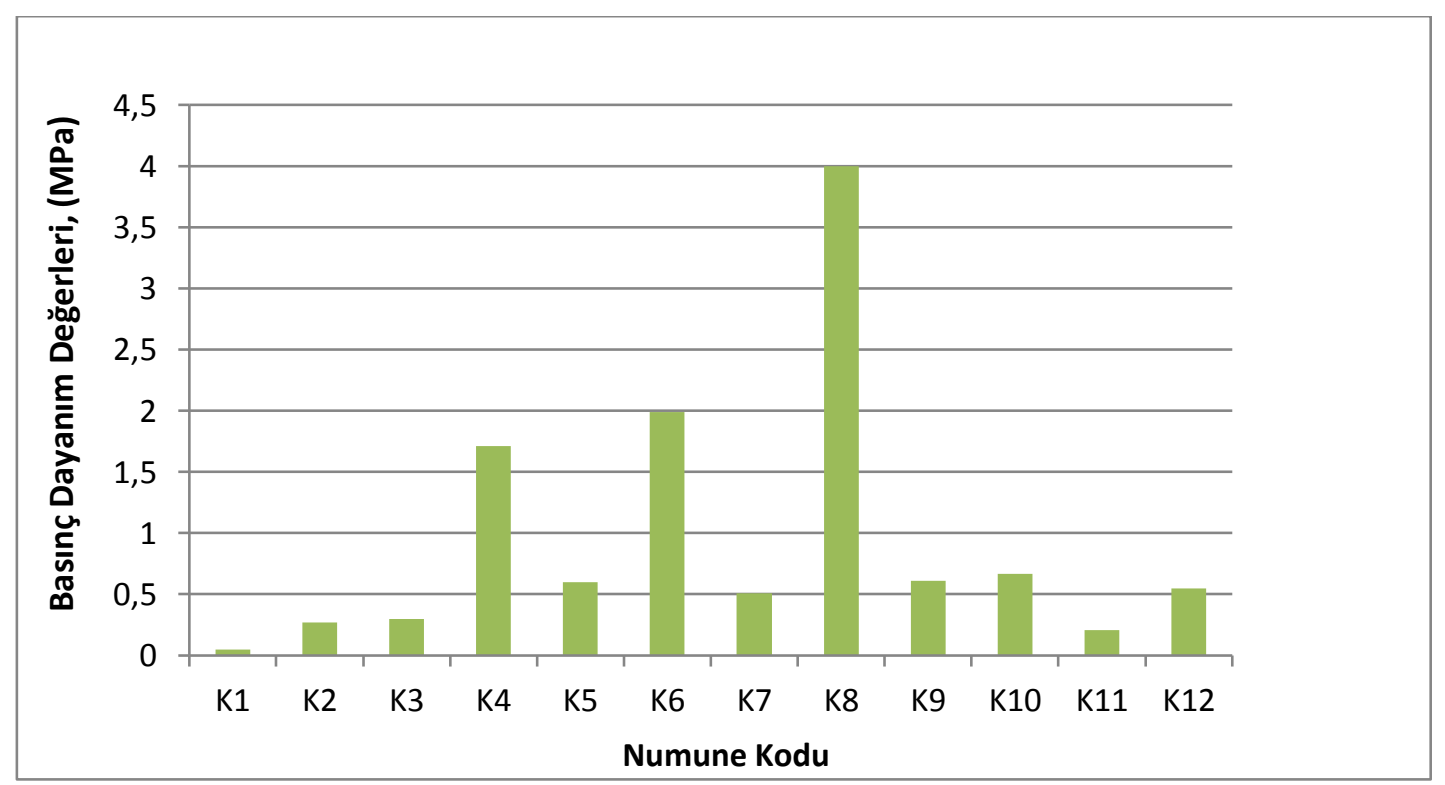

Şekil 20. Kompozit numunelerin basınç dayanımı değerleri

Bitüm esaslı kompozit numunelerde en yüksek basınç dayanımı \%80 meşe kabuğu içeren K4 numunesinde 1.71 MPa olarak elde edilmiştir. Basınç dayanımı değerleri Lebedev ve ark. (2018) 
tarafından bitüm esaslı kompozitler üzerine yapılan çalışmada bulunan değerler ile örtüşmektedir [22]. Çimento esaslı kompozitlerde ise en yüksek basınç dayanımı \%12 uçucu kül, \%12 pomza, \%12 PVC atık, \%12 talaş içeren K8 numunesinde $4 \mathrm{MPa}$ olarak elde edilmiştir. Çimento esaslı kompozitlerin basınç dayanımı değerleri Yıldırım ve Baba (2018) tarafından yapılan çalışmaya [23] kıyasla oldukça yüksektir. Ayrıca, PVC polimerik atık malzemenin içeriğinin artmasıyla mekanik özelliklerinde de olumlu sonuçlar gözlenmiştir.

\section{B. ULTRASES HIZI DEĞERLERI}

Bitüm ve çimento esaslı kompozit numunelerin ultrases hızı değerleri Şekil 21'de grafiksel olarak gösterilmiştir.

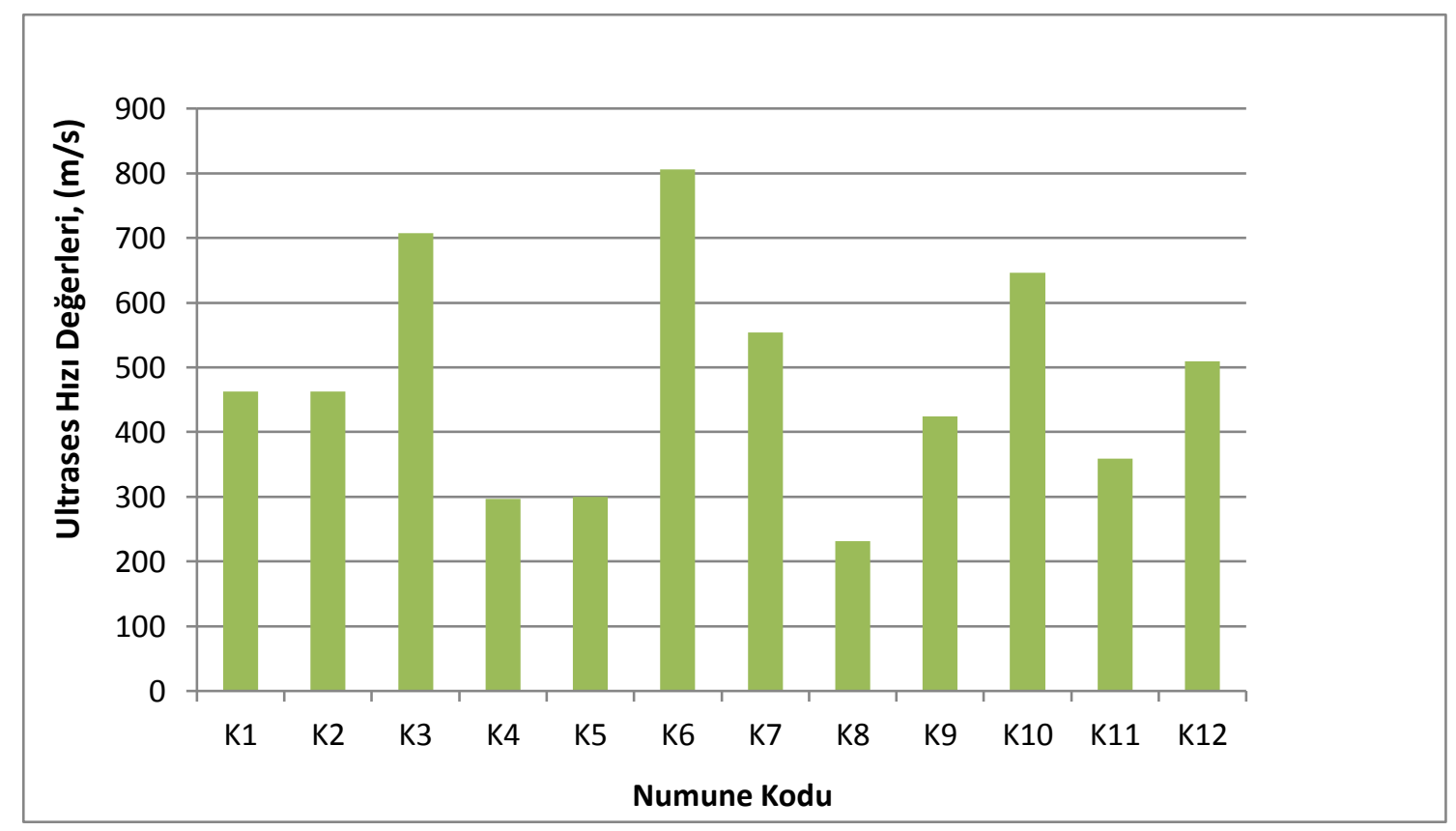

Şekil 21. Kompozit numunelerin ultrases hızı değerleri

Bitüm esaslı kompozit numunelerde en düşük ultrases hızı değeri \%80 meşe kabuğu içeren K4 numunesinde $297 \mathrm{~m} / \mathrm{s}$ olarak elde edilmiştir, en yüksek ultrases hızı değeri ise K3 numunesinde $700 \mathrm{~m} / \mathrm{s}$ olarak elde edilmiştir. Meşe kabuğu içeriği bakımından yakın oranlara sahip olan K3 ve K4 karışımlarının ultrases hızı değerlerinde belirgin bir fark olması K4 numunesinin yüzeyin plastik bağlayıcı harçla sıvanmasından kaynaklanmaktadır. Çimento esaslı kompozitlerde ise en düşük ultrases hızı değeri \%12 uçucu kül, \%12 pomza, \%12 PVC atık, \%12 talaş içeren K8 numunesinde $231 \mathrm{~m} / \mathrm{s}$ olarak, en yüksek ultrases hızı ise \%26 pomza, \%14 talaş içeren K6 numunesinde $806 \mathrm{~m} / \mathrm{s}$ olarak elde edilmiştir. Kompozit numunelerde basınç dayanımı ile ultrases hızı değerleri arasında belirgin bir ilişki kurulamaması odun ve polimer esaslı katkılardan kaynaklanmaktadır. Kompozit numunelerde elde edilen düşük ultrases hızı değerleri üretilen malzemelerin ses yalıtım malzemesi olarak kullanılabileceğini göstermektedir. K8 kompozit numunesinin basınç dayanımının yüksek, ultrases hızının ise düşük çıkması yalıtım malzemesi olarak kullanım potansiyelini arttırmaktadır. Bitüm ve çimento esaslı kompozitlerin ultrases hızı değerleri Binici (2016) tarafından yapılan çalışmada elde edilen atık mukavva, alçı, pomza, perlit, vermikülit ve zeolit esaslı kompozitlerin ultrases hızı değerleri ile örtüşmektedir [24]. 


\section{ISI GEÇIRGENLİK DEĞERLERİ}

Üretilen kompozit numunelerin 1sı geçirgenlik değerleri Şekil 22'de grafiksel olarak gösterilmiştir.

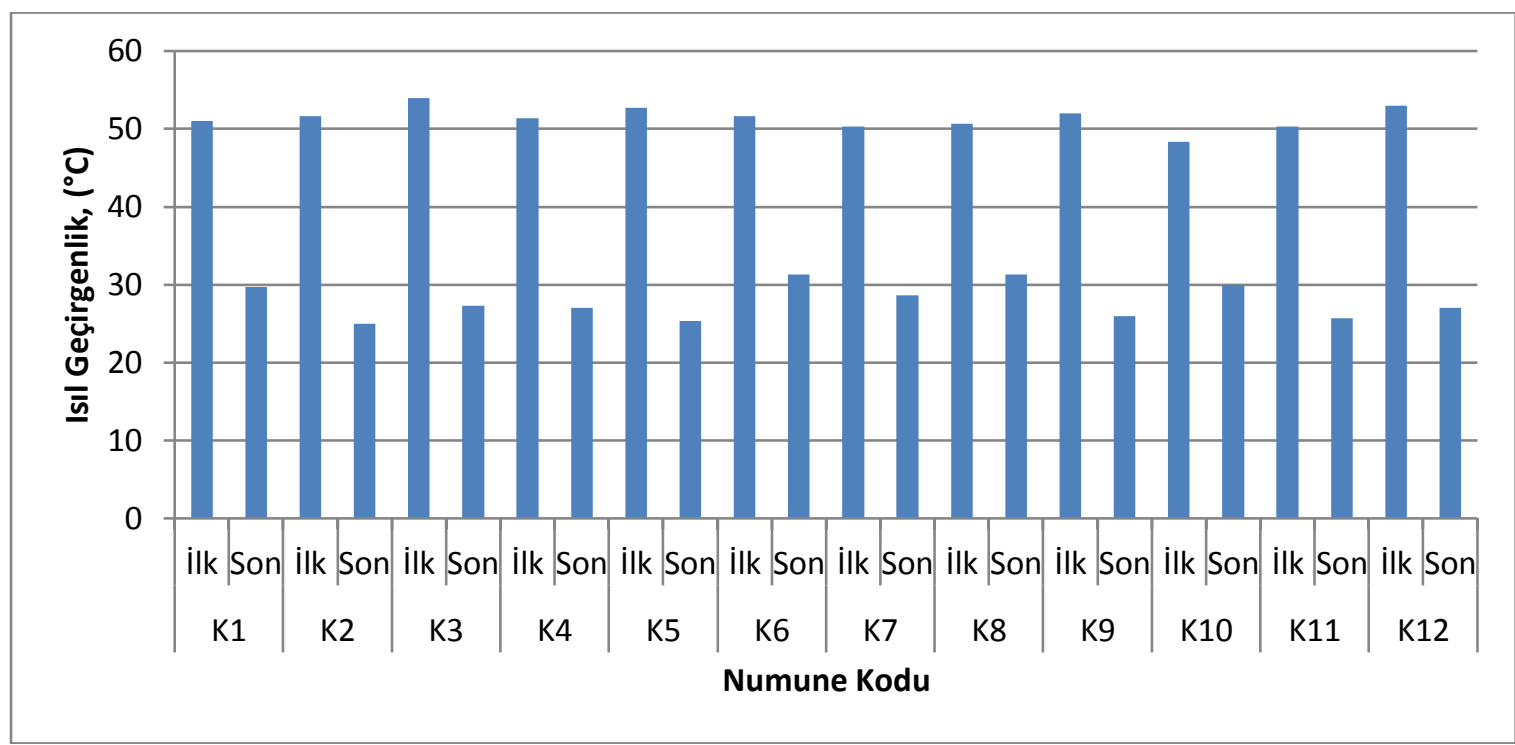

Şekil 22. Kompozit numunelerin lsı geçirgenlik değerleri

Bitüm esaslı kompozit numunelerde en düşük sıcaklık geçişi $26.67^{\circ} \mathrm{C}$ ile $\% 30$ talaş ve $\% 30$ meşe kabuğu içeren K2 numunesi ve \%77 meşe kabuğu içeren K3 numunesinde elde edilmiştir. Çimento esaslı kompozit numunelerde en düșük sicaklık geçiși $27^{\circ} \mathrm{C}$ ile $\% 27$ pomza ve $\% 19$ talaş içeren K5 numunesinde elde edilmiştir. Kompozit numunelerde elde edilen düşük 1sı geçirgenlik değerleri, üretilen kompozitlerin 1sı yalıtım malzemesi olarak kullanılabileceğini göstermektedir.

\section{NUMUNELERIN FİZIKSEL ÖZELLİKLERİ}

Üretilen kompozit numunelerin birim hacim ağırlık değerleri Şekil 23'de grafiksel olarak gösterilmiştir. Üretilen numunelerin hafif olduğu görülmektedir. Bu nedenle yapının ölü ağırlığına fazla etki etmeyecek ve deprem yükünü arttırmayacaktır.

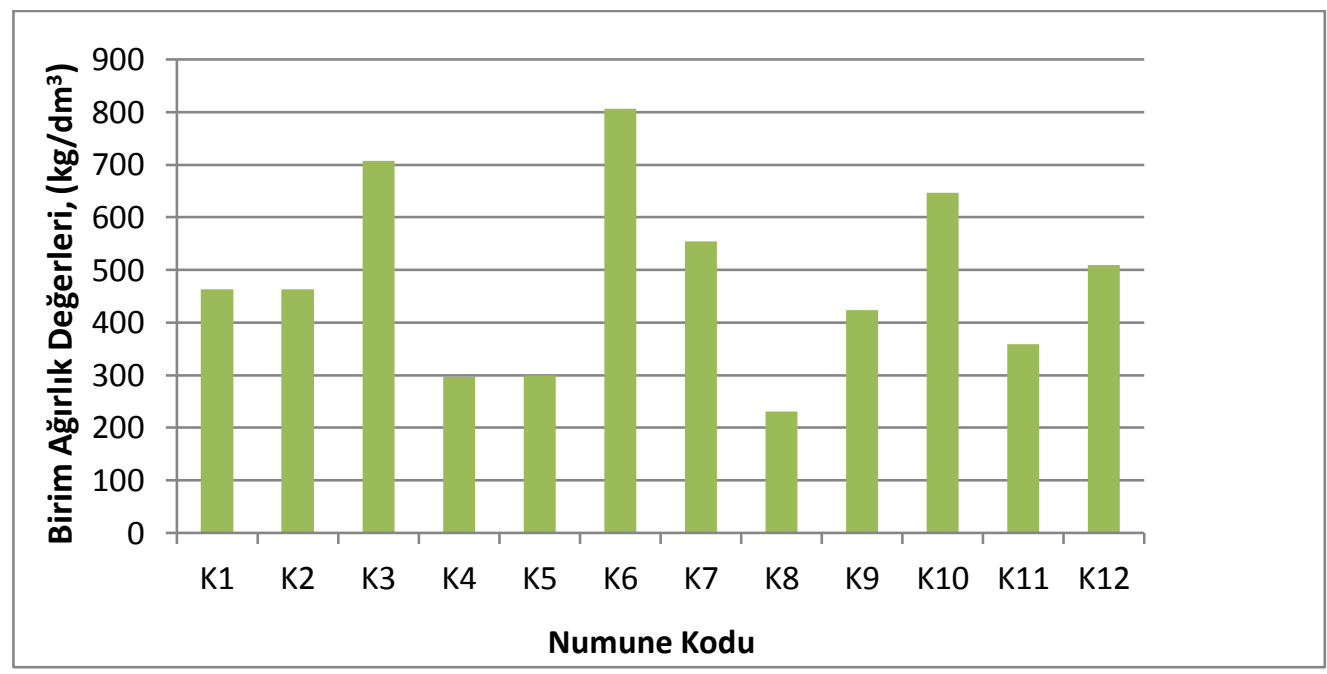

Şekil 23. Kompozit numunelerin birim ă̆ırlı değerleri 


\section{IV.SONUC}

Deney sonuçlarına göre üretilen kompozit numuneler 1S1 yalıtımı açısından tatmin edici sonuçlar vermiştir. Bu sonuçlara göre 1sı geçirgenlik değerlerinde çoğu numunede verilen sıcaklığın yaklaşık olarak \%50'sini absorbe etmiştir. Üretilen kompozitler 1s1 yalıtım malzemesi olarak iç duvarlarda kullanılabileceği ortaya çıkarılmıştır. Ayrıca kompozitler çok hafif malzemeler olduğundan binanın ölü ağırlığında ve dolaysısıyla deprem yükünde önemli bir artışa neden olmayacaktır. Kompozit malzemelerin boşluklu yapısından dolayı ses yalıtımı açısından da başarılı sonuçlar alınmıştır. Üretilen kompozit malzemelerin ses yalıtım değerleri betona veya literatürde incelenen diğer kompozitlere kıyasla oldukça düşüktür. Basınç dayanımı açısından incelendiğinde, elde edilen değerler kapsamlı çalışmalarla geliştirilmeye açıktır. Yapılan deneysel çalışamalar sonucunda, ülkemizde yeterince değerlendirilemeyen bazı doğal ve endüstriyel atıkların yalıtım teknolojisinde kullanılabileceği ve bunun sonucunda önemli ölçüde enerji tasarrufu yapılabileceği ortaya çıkarılmıştır.

\section{KAYNAKLAR}

[1] M.V. Madurwar, R. V. Ralegaonkar, S. A. Mandavgane, "Application of agro-waste for sustainable construction materials: a review" Construction and Building Materials, vol.38; pp. 872$878,2013$.

[2] J. Younquist, H,Spelter, P.Chow. "Agricultural fibres in composition panels" In: Proceedings $B$ of the 27th international particleboard/composite materials symposium, Pullman, WA: Washington State University; 30-31 March pp. 133-52, 1993.

[3] P. Lertsutthiwong, S. Khunthon, K. Siralertmukul, K. Noomun, S. Chandrkrachang, "New insulating particleboards prepared from mixture of solid wastes from tissue paper manufacturing and corn peel” Bioresour Technology; vol.99: pp. 4841-5, 2008.

[4] N.Stone, "Thermal performance of straw bale wall systems", Ecol Build Net (EBNet), ss.1-7, 2003.

[5] J. Faustino, L. Pereira, S. Soares, D. Cruz, A. Paiva, H.Varum, J. Ferreira, J. Pinto, "Impact sound insulation technique using corn cob particleboard ", Construction and Building Materials, vol.37 pp. 153-159, 2012.

[6] N. Soon-Ching, L. Kaw-Sai "Thermal conductivity of newspaper sandwiched aerated lightweight concrete panel”. Energy Building; vol.42, pp. 2452-6. 2012.

[7] C. Hasse, M. Grenet, A. Bontemps, R. Dendievel, H. Sallée, "Realization, test and modeling of honeycomb wallboards containing a phase change material" Energy Building, vol.43, pp. 232-8, 2011.

[8] B. Yeşilata, P. Turgut, Y. Iş1ker, "Atık Polimerik Malzeme Katkı1ı Betonun Yalıtım Özelliğinin Deneysel Olarak İncelenmesi ”, Iss Bilimi ve Tekniği Dergisi, c. 26 s.1, ss.15-20, 2006.

[9] H. Binici, M.H. Alma, R. Gemci ve M.Y. Durgun "Atık Polietilen (PE) bardaklardan üretilen çimentosuz harçların fiziksel ve mekaniksel özellikleri”" Yapı Teknolojileri Elektronik Dergisi, c.7, s.1, ss.71-79, 2011.

[10] Z. Z. Ismail, E. A. AL-Hashmi, "Use of waste plastic in concrete mixture as aggregate replacement”, Waste Management, vol.2; no.28, pp. 2041-2047, 2008. 
[11] S.V. Joshi, L.T. Drzal, A.K. Mohanty, S. Arora. "Are natural fibre composites environmentally superior to glass fibre reinforced composites," Compos Part AAppl, vol. 35, pp.371-376, 2004.

[12] S.P. Raut, R.V. Ralegaonkar, S.A. Mandavgane. "Development of sustainable construction material using industrial and agricultural solid waste: a review of waste-create bricks composites", Construction and Building Materials, vol.25, pp. 4037-4042, 2011.

[13] A. Pappu, M. Saxena, R. Asolekar Shyam, " Solid wastes generation in India and their recycling potential in building materials", Building Enviroment; vol. 42, pp. 2311-2320, 2007.

[14] C. Gyoung-Seok, K. Jae-Sik, J. Lee Young-Sun, Eon S., Sohnb,Jang-Yeul “ An experimental study on thermal properties of composite insulation", Thermochimica Acta, vol. 455, pp.75-79. 2007.

[15] G. Kestur Satyanarayana, G.C. Gregorio Arizaga, Wypyc. Fernando h, " Biodegradable composites based on lignocellulosic fibers-An overview", Progress in Polymer Science, vol.34, pp. 982-1021, 2009.

[16] H. Binici, " Investigating Sound Insulation, Thermal Conductivity and Radioactivity Of Chipboards Produced With Cotton Waste, Fly Ash and Barite", Construction and Building Materials, vol. 30, pp. 826-832. 2012.

[17] N. Toydemir, Composite Construction Materials, J. Compos Const. Compon Insul, vol.80, pp. 39-43, 1988.

[18] M. Şahmaran, C.Victor Li, "Durability properties of micro-cracked ECC containing high volumes fly ash," Cement and Concrete Research, vol.39, pp.1033-1043, 2009.

[19] TS EN 12390-3, “'Beton-Sertleşmiş Beton Deneyleri-Bölüm 3: Deney numunelerinin basınç dayanımının tayini”, Türk Standartları Enstitüsü, Ankara, 2019.

[20] ASTM C597-16, "Standard Test Method for Pulse Velocity Through Concrete”, ASTM International, West Conshohocken, PA, 2016.

[21] TS 825, “'Binalarda 1sı yalıtım kuralları. Türk Standartları Enstitüsü, Ankara, 2013.

[22] M.S. Lebedev, N. I. Kozhukhova, I.L. Chulkova, "Effect of phase and size characteristics of fly ash from power station on properties of bitumen composites", 2nd International Conference on Energy Materials and Applications, IOP Conf. Series: Materials Science and Engineering, vol. 222 pp:012005 2017 doi:10.1088/1757-899X/222/1/012005.

[23] S. T. Yıldırım, E. Baba, "Bims Agregalı ve Genleştirilmiş Perlit Agregalı Hafif Kompozit Harçların Özelliklerinin Deneysel Olarak İncelenmesi", Koc. Üni. Fen Bil. Der., c.1, s.1, ss.47-52, 2018.

[24] H. Binici, A. Mukavva, "Alçı, Pomza, Perlit Vermikülit ve Zeolit ile Yapılan Kompozitlerin Yangın Direncinin Araștırılması”, Çukurova Üniversitesi Mühendislik Mimarlık Fakültesi Dergisi, c.31, s.1, ss. 1-10, 2016 